\title{
Changes in some physical characteristics of the digesta in the reticulo-rumen of cows fed once daily
}

\author{
By E. W. EVANS, G. R. PEARCE*, J. BURNETT AND \\ SUSAN L. PILLINGER \\ National Institute for Research in Dairying, Shinfield, Reading RG2 $9 A T$ \\ (Received 3 May 1972-Accepted 3 November 1972)
}

\begin{abstract}
1. Three cows were given 3,5 or $7 \mathrm{~kg}$ hay once daily in a Latin-square design, and samples of digesta from four sites in the rumen and onc site in the reticulum were taken at six times within the $24 \mathrm{~h}$ period after the feed. Dry-matter content and distribution of particle size and of particle density were measured for each sample. The changes in these measurements with time were studied. The incidence of rumination was also recorded.

2. Dry-matter contents of samples ranged from i 5 to $3 \%$. Values for samples from the dorsal sacs of the rumen were considerably higher than those for samples from the ventral sites; they also changed more with time after feeding and with level of feeding.

3. Particles were fractionated by sieving into six size groups with mean dimensions ( $\mathrm{mm}$ ) of $9.3 \times 0.8,4.4 \times 0.6,2.6 \times 0.3,1.6 \times 0.25,0.5 \times 0.1$ and smaller than $0.5 \times 0.1$. Coarse particles occurred at highest concentrations in the dorsal sacs of the rumen and responded to effects of time and level of feeding; smaller particles showed less response.

4. Particle densities ranged from $800 \mathrm{~g} / 1$ to $\mathrm{I} 500 \mathrm{~g} / \mathrm{l}$. The proportions of low-density particles were higher in samples from the dorsal sacs of the rumen than in samples from ventral sites; the latter samples had higher proportions of high-density particles than of low-density particles. The changes which occurred are discussed.

5. The density of coarse particles tended to be low and that of fine particles tended to be high.

6. Rumination started at the time of maximum concentration of particles of low density and minimum concentration of particles of high density. Conversely, rumination ended when the concentration of the low-density particles was a minimum and that of the dense particles a maximum.

7. The results are discussed in relation to the possible movement of particles within the reticulo-rumen and the kinetics of particle breakdown.
\end{abstract}

Schalk \& Amadon (1928) described in some detail the structure of the reticulorumen, made observations on its functioning and referred to some of the physical characteristics of its contents for animals given different types of ration. Since then a number of other workers have added to this basic information (e.g. Magee, 1932; Balch, 1949, 1958; Balch \& Kelly, 1950; Nichols, 1959; Campling \& Freer, 1962; Welch, I965; Pearce, 1967 ; Troelsen \& Campbell, 1968).

The rate of passage of digesta through the reticulo-rumen and the rate of breakdown of digesta in that organ are important determinants of the efficiency of digestion and of the rate of rumen emptying (Balch, 1950). Both rate of passage and rate of breakdown appear to be markedly influenced by the physical characteristics of the digesta. Knowledge of the factors influencing the physical characteristics will be useful in understanding the effects of practices such as grinding, pelleting and wafering of roughages, the 'protection' of nutrients from digestion in the rumen, the granulation of trace minerals and the capsulation of drugs, medicinal compounds and inert fillers.

* Present address: School of Agriculture, University of Melbourne, Parkville, Victoria, Australia. 
Such knowledge is also valuable in understanding the factors influencing the voluntary intake of foods.

However, in spite of these investigations little is known of the progressive changes which occur, with time, in the physical characteristics of reticulo-rumen digesta in the course of normal digestive processes. In the study reported here circadian changes in dry-matter content, distribution of particles with different density and size were measured in cows given hay once daily. The incidence of rumination was also measured.

\section{EXPER I MEN T AL}

\section{Animals and treatments}

Three adult, non-lactating Friesian cows (nos. Io, I 3 and 33 ) each fitted with a rumen fistula, were held in individual stalls in an enclosed building. The only food used was pasture hay with a chemical composition ( $\mathrm{g} / \mathrm{kg}$ dry matter) as follows: crude protein 66 , crude fibre 382 , ether extract 12 , ash 59 , nitrogen-free extract $48 \mathrm{I}$.

At 09.00 hours (changed to 08.30 hours in some instances; see below) the cows were given either 7,5 or $3 \mathrm{~kg}$ (air-dry weight) of the hay (designated $\mathrm{H}, \mathrm{M}$ and $\mathrm{L}$ levels respectively) according to their allocation in a $3 \times 3$ Latin square design. Each period was of $2 \mathrm{I} d$ duration. The cows on the $\mathrm{M}$ and $\mathrm{L}$ levels of feeding usually finished eating their rations at approximately I I.00 and ro.00 hours respectively, but those on the $\mathrm{H}$ level did not behave uniformly. Cow 33 consumed the $7 \mathrm{~kg}$ hay by I I. 30 hours and this was taken as the time, each day, after which no further consumption of food would be permitted. However, the rates of eating of cow Io (period 2) and cow 13 (period 3 ) on the $H$ level of feeding were less than that of cow 33 , and to maintain a high level of intake these two cows were given an extended period of feeding, namely 08.30-Ir.30 hours. Even so, they did not always consume all the ration; during the ro d period immediately preceding sampling, cow ro consumed, on average, $6 . \mathrm{I} \mathrm{kg}$, and cow $136.0 \mathrm{~kg}$, whereas on the actual sampling days they consumed $6.0 \mathrm{~kg}$ and $5.75 \mathrm{~kg}$, respectively.

Water was available for only one period daily, from 09.00 to 12.00 hours. During the ro $d$ period immediately before sampling the daily water consumption averaged 281 for cows on the $H$ level of feeding, 221 for those on the M level, and I6 1 for those on the $L$ level.

No food, therefore, entered the reticulo-rumen after I I.3o hours each day and no water after 12.00 hours each day.

\section{Measurements}

Dry-matter content, and the densities and sizes of particles, were measured on samples taken from various sites in the rumen and reticulum at various times after feeding; times at which the animals ruminated were also recorded.

Sampling procedure. On the 2ist day of each period, samples of digesta were taken from each cow from four positions in the rumen (A, anterior dorsal sac; B, caudodorsal blind sac; $C$, caudo-ventral blind sac; $D$, anterior ventral sac) and from the reticulum $(E)$ at six times between the end of feeding and feeding time the next day. 


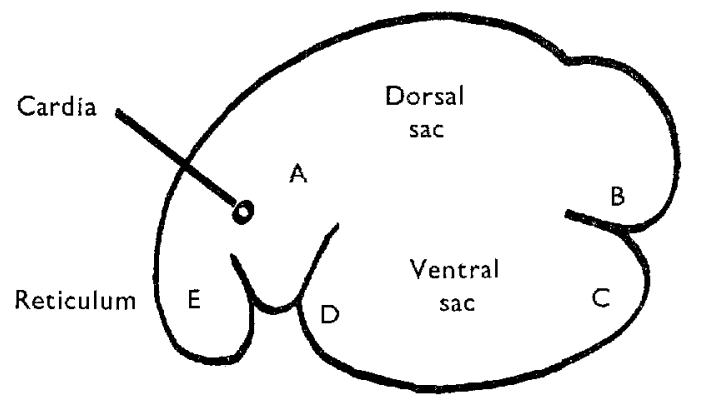

Fig. r. Diagrammatic representation of the reticulo-rumen showing sampling sites.

The positions are indicated in Fig. I. Sampling commenced at I I.30, I4.00, I7.00, $21.00,05.00$ and 09.00 hours. The cows were always sampled in order of the level of feeding: L, M, H. Sampling from one cow and the immediate processing of the samples occupied approximately $30 \mathrm{~min}$, so that the times given above applied to $\mathrm{L}$ cows whereas the times for $\mathrm{M}$ cows were $30 \mathrm{~min}$ later and those for $\mathrm{H}$ cows $60 \mathrm{~min}$ later. Samples were taken by means of a plastic container $70 \mathrm{~mm}$ in diameter at the top, $50 \mathrm{~mm}$ in diameter at the bottom and $70 \mathrm{~mm}$ high and with a capacity of $\mathrm{I} 60 \mathrm{ml}$. A close-fitting lid prevented contamination during entry and removal of the container. In sampling, the cannula plug was removed, the arm inserted into the rumen and the required sampling position established by locating prominent structures in the rumen wall. For sampling from the reticulum, the base of the container was rested on the reticular side of the rumino-reticular fold and the sample was taken with the container in a horizontal position. At each sampling the lid of the container was removed only when the container was in the required position and the lid was replaced before withdrawing the container. Where the digesta were of a fluid consistency, material was allowed to flow freely into the container; where they were not fluid, material was raked into the container with the fingers.

Subsampling. The five samples from a cow were divided in the laboratory into three parts for determination of dry matter, particle densities and particle sizes.

Special apparatus was used for subsampling. It consisted of a metal trough which could be subdivided into three water-tight compartments after the sample had been distributed and uniformly mixed along the length of the trough. Samples having no free water component were not treated in this way; they were spread evenly on a flat surface and small amounts were picked out until the required divisions were achieved. After subsampling, formalin was added to each fraction and, when not processed immediately, the sample was placed under refrigeration at $2^{\circ}$.

Dry-matter determinations. Subsamples were dried at about $80^{\circ}$ for $48 \mathrm{~h}$.

Particle size distributions. The measurements were made in an apparatus designed and constructed by Turner \& Newall Ltd (Asbestos Fibre Laboratory, c/o Turners Asbestos Cement Co. Ltd, PO Box 22, Trafford Park, Manchester Mi7 I RU). This consisted essentially of a set of five wire-mesh screens ( $90 \mathrm{~mm}$ in diameter) arranged vertically in order with the coarsest screen on top. A jet of water entering the top screen and passing through succeeding screens to an outlet at the bottom washed the 
Table I. Repeatability of particle size fractionation of ten subsamples taken from one well-mixed sample of reticulo-rumen digesta of cows

(Amount of dry fibrous material in each size range expressed as $\%$ of the dry matter of the subsample)

$\begin{array}{crc}\text { Sieve no. } & \text { Mean } & \begin{array}{c}\text { Standard } \\ \text { deviation }\end{array} \\ \text { I } & 44.3 & 2 \cdot 9 \\ 2 & 8 \cdot 9 & \mathrm{I} \cdot 6 \\ 3 & 12 \cdot \mathrm{r} & 0.5 \\ 4 & 8.8 & 0.5 \\ 5 & 8 \cdot 4 & 0.7 \\ 6 & 17.5 * & 0.8\end{array}$

digesta particles over the mesh surfaces, while a mechanical device which rotated each screen and activated soft rubber brushes assisted in spreading the particles. The conditions under which the sieving machine was operated were such that particles suffered little mechanical damage.

A subsample for size fractionation was placed on the top screen, the water-flow was adjusted to a predetermined pressure and the screen rotation and brush movement were set in motion. After a fixed period of time, taken after testing as $2 \mathrm{~min}$, the machine was stopped and the material on each screen washed on to a tared filter-paper for drying. In this way the sample was separated into sections of six particle sizes, the weight of the sixth fraction being obtained by difference.

The mesh sizes of the screens were selected arbitrarily to yield fractions which were visibly different in size. Sieves having square holes of sides $2.4 \times \mathrm{IO}^{-3}, \mathrm{I} \cdot 2 \times \mathrm{IO}^{-3}$, $6 \times 10^{-4}, 3 \times 10^{-4}$ and $7.5 \times 10^{-5} \mathrm{~m}$ were used. The mean dimensions of particles collected on the five screens were estimated by measuring 500 particles from a mixed sample from a number of fractionations; these were $(\mathrm{mm}) 9.3 \times 0.8,4.4 \times 0.6$, $2.6 \times 0.3,1.6 \times 0.25$ and $0.5 \times 0.1$.

The repeatability of this fractionation procedure was estimated by taking a sample of rumen contents from the dorsal region of the rumen of a cow, subdividing it into ten subsamples and putting each subsample through the apparatus under the same conditions as adopted for the routine processing. The results are shown in Table I. It would be expected that subsamples with smaller proportions of coarse material would show less variation than this.

Particle density distributions. The density distributions of particulate matter in the subsamples were determined by means of density-gradient columns made up of mixtures of ethanol and carbon tetrachloride. In the making up of a column, ethanol and carbon tetrachloride, held in separate but connected flasks, were allowed to drain slowly into an opening at the bottom of a glass cylinder $500 \mathrm{~mm}$ high and $70 \mathrm{~mm}$ in diameter. The mixture of liquids entering the cylinder was, to begin with, almost pure ethanol which was displaced upwards by a mixture containing increasing proportions of carbon tetrachloride, until the cylinder was filled. In this way, columns with densities ranging from approximately $800 \mathrm{~g} / 1$ at the top to $1500 \mathrm{~g} / 1$ at the bottom 
were established. Each column was calibrated by means of glass beads of known density. Density did not vary linearly with depth below the surface of the column and in practice a graph was drawn relating density to depth for each column. A battery of three columns was used at any one time. These were fitted into a closed box and were maintained at $37^{\circ}$ during the time of filling $(\mathrm{I}-\mathrm{I} \cdot 5 \mathrm{~h})$ and of the density measurement.

The following procedure was adopted for routine measurements. A subsample with a component of free liquid was strained through a 200 mesh screen, by means of a water pump; this step was omitted for a relatively dry subsample. The subsample was then added to the top layer of liquid in a column and the column was allowed to equilibrate for $30 \mathrm{~min}$. After this time the positions of the glass beads, of which six to eight were used in each column, were recorded. To remove the particulate material from the column, carbon tetrachloride was introduced slowly at the bottom of the cylinder, causing the liquid and suspended particles further up the column to be displaced upwards and to overflow into a number of flasks held successively under a lip at the top of the cylinder. Sufficient carbon tetrachloride was introduced to raise the column a measured distance, usually $60 \mathrm{~mm}$, before one flask was removed and another substituted. After all the particulate material had been removed, the contents of each flask were filtered so that the digesta particles were retained on a previously weighed filter-paper for drying and weighing. In this way, each subsample was separated into six to nine fractions, the density ranges of which were determined by reference to the density curve obtained from the glass beads. By using three such columns, it was possible to process six to nine subsamples daily.

In preliminary testing it was established that certain limitations are inherent in this procedure. First, reagents such as ethanol and carbon tetrachloride may have some effect on the digesta, if only in replacing some of the water held in the particles. 'The densities recorded, therefore, were likely to be those of the solid vegetative matter rather than of particles containing rumen fluid. It might be expected that the use of water-immiscible liquids in the column would overcome this problem but, in fact, it was found that this prevented separation of individual particles and did not permit particles to distribute themselves throughout the column. In addition, ethanol and carbon tetrachloride may dissolve some of the vegetative constituents such as fats and pigments. However, in view of the low content of diethyl ether extract in the food, this could not represent a serious source of error. Secondly, allowing a period of 30 min for equilibration of the particles within the column was recognized as a compromise since preliminary tests showed that, in fact, settling would continue for $24 \mathrm{~h}$ or more. Thirdly, carbon tetrachloride is hazardous to handle owing to its toxic nature. Special precautions need to be taken with the provision for ventilation in the working area.

Rumination measurements. At 09.00 hours on the day of sampling, each cow was fitted with a head harness bearing a small rubber balloon positioned at one side of the lower jaw. An airtight tube transmitted jaw movement pressures to a rubber tambour activating a pen which made appropriate tracings on paper moving at the rate of $12.5 \mathrm{~mm} / \mathrm{min}$. The incidence of rumination was measured in this way for the duration of the sampling day. 
Table 2. Mean dry-matter contents (weight $\%$ ) of samples of digesta from sites in different parts of the reticulo-rumen in three cows on three levels of hay $(H, M$ and $L)$

(Values for sites $A$ and $B$, and for sites $C$ and $D$, have been averaged)

\begin{tabular}{|c|c|c|c|c|c|c|c|c|c|c|c|c|}
\hline \multirow{3}{*}{$\begin{array}{l}\text { Sampling } \\
\text { time* }\end{array}$} & \multicolumn{12}{|c|}{ Level of feeding } \\
\hline & \multicolumn{3}{|c|}{$\mathrm{H}$} & \multicolumn{3}{|c|}{ M } & \multicolumn{3}{|c|}{ L } & \multicolumn{3}{|c|}{ All } \\
\hline & $A$ or $B$ & $C$ or $D$ & $E$ & $A$ or $B$ & $C$ or $D$ & $E$ & $A$ or $B$ & $C$ or $D$ & $E$ & $A$ or $B$ & $C$ or $D$ & $E$ \\
\hline 2 & 15.3 & $4 \cdot 2$ & 3.7 & $\mathrm{r} 3.5$ & $3 \cdot 6$ & $4 \cdot 5$ & $\mathrm{~T} 2 \cdot 2$ & $3 \cdot 4$ & $3 \cdot 6$ & 1 3.7 & $3 \cdot 7$ & $3 \cdot 9$ \\
\hline $4 \cdot 5$ & 15.6 & $3 \cdot 5$ & 4.8 & 13.9 & $3 \cdot 8$ & 4.0 & II $\cdot 9$ & 3.9 & $4 \cdot I$ & 13.8 & 3.8 & $4 \cdot 3$ \\
\hline 7.5 & 13.8 & $4 \cdot I$ & $5 \cdot 9$ & $\times 4.0$ & $3 \cdot 7$ & 4.0 & $\mathrm{I} 2 \cdot \mathrm{I}$ & 3.5 & 4.4 & $13 \cdot 3$ & 3.8 & $4 \cdot 8$ \\
\hline II. 5 & 15.2 & 49 & $5 \cdot \mathrm{I}$ & $12 \cdot 6$ & $5 \circ$ & $5 \cdot I$ & 10.9 & $4 \cdot 4$ & 44 & $12 \cdot 9$ & 47 & $4 \cdot 9$ \\
\hline $19 \cdot 5$ & 13.4 & $5 \cdot 4$ & $6 \cdot 7$ & II 8 & $5 \cdot 6$ & $6 \cdot 5$ & 10.0 & 6.0 & $5 \cdot 0$ & $\operatorname{II} \cdot 7$ & 577 & $6 \cdot 1$ \\
\hline 23.5 & $11 \cdot 5$ & $5 \cdot 4$ & $5 \cdot 8$ & 10.6 & 5.9 & $6 \cdot I$ & $10 \cdot 0$ & 4.8 & $4 \cdot 6$ & 10.7 & 5.4 & $5 \cdot 5$ \\
\hline All times & I4. I & $4 \cdot 6$ & $5 \cdot 3$ & $12 \cdot 7$ & $4 \cdot 6$ & 5.0 & II I I & $4 \cdot 3$ & $4 \cdot 5$ & $12 \cdot 7$ & 4.5 & $4 \cdot 9$ \\
\hline
\end{tabular}

Test for statistical significance. Student's $t$-test was used to test for significance of differences betwcen sets of results for different cows, levels of feed, size of particles and density of particles. Levels of significance are given in the text except where the level of significance is above $5 \%$, when the difference is said to be not significant.

\section{RESULTS}

The experiment yielded a large amount of information on dry-matter percentages, concentrations of particles of six size ranges and six to nine density ranges in samples of digesta, taken at six sampling times, from five positions in the reticulo-rumen for each cow, at three different levels of feeding. It is not possible to present all the detailed results in this paper. Instead, it is proposed to illustrate in general terms how dry-matter percentages, particle sizes and particle densities changed with time and to present some analyses of specific aspects.

For the purpose of comparing changes in these measurements with time for animals on different treatments, the concept of 'mean feeding time' was adopted such that the time measured from half-way between the start of feeding ( 09.00 or $08.3 \circ$ hours) and the end of feeding (IO.00, I I.00 or I I.3o hours, depending upon the level of feeding) was taken as zero time ( $T 0$ ), and sampling times were expressed in hours from this time. This permitted results to be compared at $T_{2}(2 \mathrm{~h}$ from the mean feeding time), $T_{4 \cdot 5}, T_{7} \cdot 5, T_{11} \cdot 5, T_{19} \cdot 5$ and $T_{23} \cdot 5$.

\section{Dry-matter percentages}

The results are given in Table 2.

The quantities of dry-matter at sites $A$ and $B$ were similar and appreciably greater than those at sites $C, D$ and $E$. There was no significant difference between the drymatter percentages at sites $C$ and $D$ on the three levels of feeding. There was a significant difference, at the $5 \%$ level, between the dry-matter percentages at sites $A$ and $B$ for cows on high and low levels of hay, but there was no significant difference between these sites on the medium level of hay. The difference between means of the dry- 


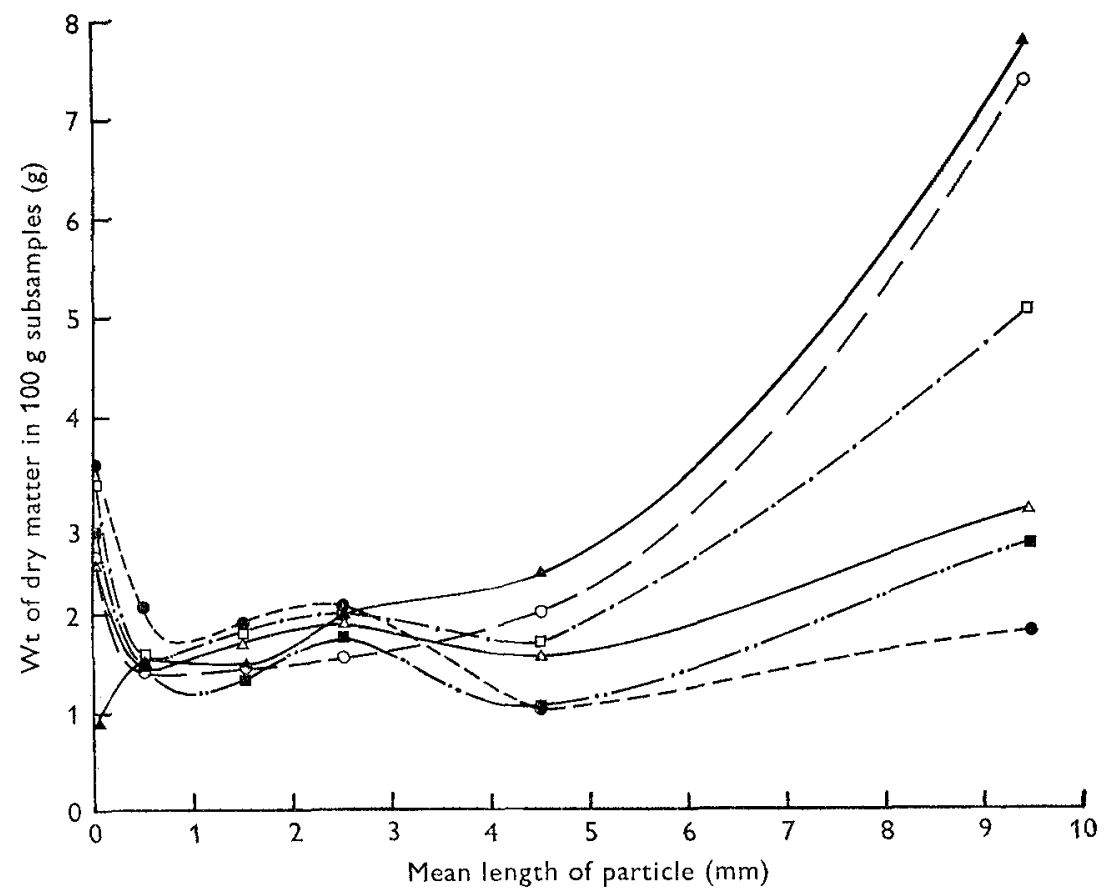

Fig. 2. Concentration, in dry matter of samples from the reticulo-rumen, of particles of different mean lengths at different sampling times for cow ro on a ration of $5 \mathrm{~kg}$ hay/d. Samples taken from dorsal site $A$. $\triangle, T_{2} ; O, T_{4} \cdot 5 ; \square, T_{7} \cdot 5 ; \triangle, T_{\text {I I }}{ }_{5} ; \bullet, T_{19}{ }_{5} ; \mathbf{\square}, T_{23} \cdot 5$.

matter percentages at sites $C, D$ and at $E$ was not significant, significant at the I \% level, and significant at the $5 \%$ level, for cows on low, medium and high levels of hay respectively.

Samples from sites $A$ and $B$ tended to decrease in dry-matter content from $T_{4} \cdot 5$ onwards, and sites $C, D$ and $E$ tended to increase in dry-matter content. Sites $A$ and $B$ reflected changes in level of feeding but sites $C, D$ and $E$ did not.

\section{Particle size distributions}

The mean dimensions of particles caught on the five screens used for size fractionations have previously been described as lying between $9.3 \times 0.8 \mathrm{~mm}$ and $0.5 \times 0 . \mathrm{Imm}$; smaller particles passed through the finest screen. Some individual particles were $30 \mathrm{~mm}$ long, others were microscopic in size. Fig. 2 indicates one way in which the results of sieving may be regarded. There was a large decrease in the concentration of coarse material with time and a small increase in the concentration of finely divided material.

To simplify the interpretation of changes occurring in the reticulo-rumen, size fractions were grouped into four: coarse (particles retained by the coarsest screen and having a mean length of $9.3 \mathrm{~mm}$ ), medium (particles retained on the next two screens and having a mean length of $3.5 \mathrm{~mm}$ ), fine (particles retained on the two finest screens and having a mean length of $\mathrm{I} \cdot 0 \mathrm{~mm}$ ), soluble and very fine (particles passing through the finest screen and having a mean length of less than $0.5 \mathrm{~mm}$ ). Although it was 
Table 3. Mean concentration (mg/g total sample) of solid matter of four size groups in samples of digesta $A-E$ in different parts of the reticulo-rumen of three cows on three levels of hay $(H, M$ and $L)$

(Values for sites $A$ and $B$ and for sites $C$ and $D$, have been averaged)

\begin{tabular}{|c|c|c|c|c|c|c|c|c|c|c|}
\hline & & & & & Levi & l of fe & & & & \\
\hline & & & $\mathrm{H}$ & & & M & & & $L$ & \\
\hline & & & mpling si & & & npling sit & & & mpling si & \\
\hline $\begin{array}{l}\text { Sampling } \\
\text { time* }\end{array}$ & $\begin{array}{c}\text { Pafticie } \\
\text { sizet }\end{array}$ & $A$ or $B$ & $C$ or $D$ & $E$ & $A$ or $B$ & $C$ ot $D$ & $E$ & $A$ or $B$ & $C$ or $D$ & $E$ \\
\hline 2 & Coarse & 62 & 5 & 3 & 50 & 4 & 4 & 46 & 3 & 3 \\
\hline & Medium & 37 & 6 & 6 & 39 & 6 & 8 & 26 & 3 & 4 \\
\hline & Fine & 32 & 9 & 8 & $3 x$ & 9 & I I & 25 & 6 & 6 \\
\hline & Soluble and very fine & 21 & $2 \mathrm{r}$ & 19 & 16 & 17 & 22 & 25 & $2 I$ & 22 \\
\hline $4 \cdot 5$ & Coarse & $5 I$ & 2 & 5 & $5 \mathrm{I}$ & 4 & 4 & 49 & 5 & 5 \\
\hline & Medium & 38 & 4 & 8 & 34 & 6 & 7 & 26 & 5 & 7 \\
\hline & Fine & 32 & 7 & 10 & $3^{\circ}$ & 8 & IO & 25 & 9 & II \\
\hline & Soluble and very fine & 35 & 23 & 2,5 & 24 & $2 \mathrm{I}$ & 19 & 19 & 20 & 18 \\
\hline $7 \cdot 5$ & Coarse & 39 & 5 & 8 & $4 \mathrm{I}$ & 4 & 7 & 43 & 3 & 7 \\
\hline & Medium & 35 & 5 & 12 & 36 & 4 & II & 28 & 4 & 9 \\
\hline & Fine & 35 & 9 & 14 & 33 & 9 & I5 & 26 & 7 & 10 \\
\hline & Soluble and very fine & 29 & 22 & 25 & 30 & 20 & $\mathrm{~T} 8$ & 25 & 22 & 18 \\
\hline$I I \cdot 5$ & Coarse & 36 & 5 & 5 & 30 & 4 & 6 & $3 \mathrm{I}$ & 4 & 6 \\
\hline & Medium & 39 & 8 & II & 35 & 8 & 12 & 26 & 8 & II \\
\hline & Fine & 39 & 13 & $\mathrm{I}_{4}$ & 35 & 12 & I6 & 27 & 12 & 14 \\
\hline & Soluble and very fine & 38 & 23 & 22 & 26 & 26 & 16 & 28 & 21 & 19 \\
\hline 19.5 & Coarse & 22 & 3 & 5 & 15 & 4 & 6 & 19 & 6 & 4 \\
\hline & Medium & 36 & II & 16 & 33 & II & I5 & 26 & II & 9 \\
\hline & Fine & 42 & 18 & 22 & 40 & 19 & 22 & $3 \mathbf{I}$ & I9 & 16 \\
\hline & Soluble and very fine & 33 & 22 & 23 & 30 & 23 & $2 \mathrm{I}$ & 24 & 23 & 22 \\
\hline 23.5 & Coarse & 19 & 5 & 6 & 17 & 5 & 5 & 20 & 5 & 4 \\
\hline & Medium & 35 & I2 & 17 & $3 \mathbf{r}$ & 12 & I5 & 26 & 9 & 8 \\
\hline & Fine & 38 & 18 & 21 & 34 & 21 & $2 \mathrm{I}$ & 29 & 15 & $I_{4}$ \\
\hline & Soluble and very fine & 23 & 20 & 14 & 25 & 20 & I9 & 24 & $2 I$ & 18 \\
\hline Mean & Coarse & 38 & 5 & 5 & 34 & 4 & 5 & 34 & 5 & 5 \\
\hline over & Medium & 37 & 8 & 12 & 35 & 8 & II & 27 & 6 & 8 \\
\hline $24 \mathrm{~h}$ & Fine & 37 & I 2 & 15 & 34 & 13 & I6 & 27 & II & I 2 \\
\hline & Soluble and very fine & 30 & $2 \mathrm{I}$ & $2 x$ & 25 & 20 & I9 & 24 & $2 \mathrm{I}$ & 20 \\
\hline
\end{tabular}

* No. of hours, measured from time half-way between beginning and end of feeding.

+ Mean length $(\mathrm{mm})$ : coarse 9.3 ; medium 3.5 ; fine $1 \cdot 0$; soluble and very fine $<0.5$.

possible to make calculations in terms of changes in concentration of dry matter only, it was considered more meaningful to consider changes in terms of the total sample, that is dry matter plus liquid. It was recognized that a change in the concentration of a particular solid fraction could be caused by changes in concentrations of other solid fractions or of changes in the liquid component. Mean concentrations from the three cows for the different times and sites are shown in Table 3 .

\section{Variation of concentration, as determined by size, with time}

Maximum concentrations of coarse particles at sites $A$ and $B$ occurred immediately after feeding, after which there was an almost uniform decrease in concentration. The rate of change of concentration was faster at site $B$, reaching a minimum at $T_{\mathrm{I} 9} \cdot 5$, 
whereas the minimum at site $A$ was reached at $T_{23} \cdot 5$. At site $C$ concentrations of coarse particles fluctuated less and showed some inconsistent patterns, whereas at sites $D$ and $E$ the minimum concentration of coarse particles occurred immediately after feeding. At the end of the $24 \mathrm{~h}$ period the concentration of coarse material in each of the dorsal sites was at least twice the maximum concentration in any of the other three sites over the whole $24 \mathrm{~h}$.

The concentrations of medium-sized particles at sites $A$ and $B$ remained relatively constant throughout the $24 \mathrm{~h}$, decreasing, at most, to about three-quarters of their values after feeding, whereas the concentrations at sites $C, D$ and $E$ increased up to six times, depending upon the site and the cow.

In general, the concentration of fine particles increased from the end of feeding to a maximum at $T_{1} 9 \cdot 5$, then decreased until the next feed. The total change in concentration at each site was approximately equal but, because of different base values, the change at sites $A$ and $B$ represented an increase of about $35 \%$, whereas at sites $C, D$ and $E$ it was about $170 \%$ of the minimum concentrations.

The changes in concentration of soluble and very fine material showed relatively small fluctuations with time. Nevertheless, a feature of the concentration changes of this fraction was a minimum either at, or soon after, feeding and a maximum between $T_{\text {II }} \cdot 5$ and $T_{19} \cdot 5$. The exact timing of the minimum seemed to be influenced by the level of feeding. The minima occurred later in the cows given $3 \mathrm{~kg} / \mathrm{d}$ than in those given either 5 or $7 \mathrm{~kg} / \mathrm{d}$, the times being $4.5,2$ and o h respectively, from the mean feeding time. The widest fluctuations in concentrations of this fraction occurred at site $B$, with nearly as much at site $A$. Least variation occurred at sites $C$ and $D$; the range of variation at $E$ was about twice that at $C$ or $D$. Although, in general, the concentration of soluble and very fine particles increased with time after feeding, there was commonly a small peak in the curve of concentration against time at $T_{4.5}$ or $T_{7} \cdot 5$, well before the concentration attained its maximum value for the cycle as a whole, and the maximum concentration occurred at all sites and for all rations at least $4 \mathrm{~h}$ before the next feed.

The mean concentration over $24 \mathrm{~h}$ of coarse particles was greater than that of other particles at sites $A$ and $B$, but at sites $C, D$ and $E$ coarse particles occurred at a lower concentration than fine particles. The concentration of the coarse particles at sites $A$ or $B$ was about eight times that at sites $C, D$ or $E$, irrespective of the level of feeding. On the other hand, the concentration of the finest grade of material in the dorsal sites was only about $20 \%$ more than in the ventral sites. Coarse material was thus confined mainly to the dorsal sac and the distribution of particles throughout the rumen became more uniform as the particles became smaller.

There were small but significant increases in concentration of all sizes of particle at sites $A$ and $B$ with increased level of feeding, but this was smaller than would be expected from the differences in intake levels, presumably because of compensating intakes of water and the secretion of saliva. There were no differences in the concentrations of any size of particle at the ventral sites $C, D$ and $E$.

Concentrations of the coarsest material at sites $A$ and $B$, and at sites $C$ and $D$, were equal. The concentration of coarse material at site $E$ was usually equal to or greater 
Table 4. Mean concentration (mg/g total sample) of solid maiter of three density groups, at the five sampling sites $A$ to $E$, for three cows on three levels of hay $(H, M$ and $L)$

\begin{tabular}{|c|c|c|c|c|c|c|c|}
\hline \multirow[b]{3}{*}{$\begin{array}{c}\text { Sampling } \\
\text { time }^{*}\end{array}$} & \multirow[b]{3}{*}{$\begin{array}{l}\text { Dcnsity } \\
\text { groupt }\end{array}$} & \multicolumn{5}{|c|}{ Level of feeding } & \\
\hline & & $\underset{\text { Sampl }}{\mathrm{f}}$ & ing site & Sampl & $\mathrm{I}$ & Sampli & ng site \\
\hline & & $A$ or $B$ & $C, D$ or $E$ & $A$ or $B$ & $C, D$ or $E$ & $A$ or $B$ & $C, D$ or $E$ \\
\hline 2 & $\begin{array}{l}\text { Low } \\
\text { Medium } \\
\text { High }\end{array}$ & $\begin{array}{l}39.0 \\
33.5 \\
40.5\end{array}$ & $\begin{array}{r}4.0 \\
6.0 \\
10.7\end{array}$ & $\begin{array}{l}46 \cdot 5 \\
24 \cdot 0 \\
49 \cdot 5\end{array}$ & $\begin{array}{r}4 \cdot 0 \\
47 \\
127\end{array}$ & $\begin{array}{l}40.5 \\
26 \cdot 0 \\
29 \cdot 0\end{array}$ & $\begin{array}{l}3 \cdot 3 \\
4 \cdot 0 \\
5 \cdot 0\end{array}$ \\
\hline $4 \cdot 5$ & $\begin{array}{l}\text { Low } \\
\text { Medium } \\
\text { High }\end{array}$ & $\begin{array}{l}56 \cdot 0 \\
39 \cdot 5 \\
21 \cdot 5\end{array}$ & $\begin{array}{l}3 \cdot 3 \\
5 \cdot 7 \\
7 \cdot 7\end{array}$ & $\begin{array}{l}56 \cdot 5 \\
31 \cdot 0 \\
26 \cdot 5\end{array}$ & $\begin{array}{r}12 \cdot 3 \\
5 \cdot 0 \\
9 \cdot 3\end{array}$ & $\begin{array}{l}66 \cdot 0 \\
18 \cdot 5 \\
16 \cdot 0\end{array}$ & $\begin{array}{l}5 \cdot 3 \\
5 \cdot 7 \\
7 \cdot 0\end{array}$ \\
\hline $7 \cdot 5$ & $\begin{array}{l}\text { Low } \\
\text { Medium } \\
\text { High }\end{array}$ & $\begin{array}{l}41 \cdot 5 \\
39 \cdot 5 \\
17 \cdot 0\end{array}$ & $\begin{array}{l}4 \cdot 7 \\
6 \cdot 3 \\
9 \cdot 0\end{array}$ & $\begin{array}{l}34.0 \\
40.0 \\
34.0\end{array}$ & $\begin{array}{r}5.7 \\
7 \cdot 0 \\
10 \cdot 7\end{array}$ & $\begin{array}{l}51 \cdot 0 \\
23 \cdot 5 \\
12 \cdot 0\end{array}$ & $\begin{array}{l}6 \cdot 0 \\
6 \cdot 3 \\
5 \cdot 3\end{array}$ \\
\hline II 5 & $\begin{array}{l}\text { Low } \\
\text { Medium } \\
\text { High }\end{array}$ & $\begin{array}{l}36 \cdot 5 \\
34 \cdot 5 \\
43^{\circ} \circ\end{array}$ & $\begin{array}{r}7 \cdot 7 \\
10 \cdot 0 \\
13 \cdot 3\end{array}$ & $\begin{array}{l}33 \cdot 5 \\
34 \cdot 0 \\
34.0\end{array}$ & $\begin{array}{r}4 \cdot 7 \\
8 \cdot 0 \\
16 \cdot 3\end{array}$ & $\begin{array}{l}32 \cdot 5 \\
34.5 \\
19.5\end{array}$ & $\begin{array}{r}8 \cdot 7 \\
7 \cdot 3 \\
10 \cdot 7\end{array}$ \\
\hline 19.5 & $\begin{array}{l}\text { Low } \\
\text { Medium } \\
\text { High }\end{array}$ & $\begin{array}{l}27 \cdot 5 \\
37 \cdot 5 \\
37 \cdot 0\end{array}$ & $\begin{array}{r}6 \cdot 3 \\
15 \cdot 0 \\
13 \cdot 0\end{array}$ & $\begin{array}{l}31 \cdot 5 \\
24 \cdot 0 \\
29 \cdot 5\end{array}$ & $\begin{array}{r}6 \cdot 0 \\
13 \cdot 0 \\
18 \cdot 0\end{array}$ & $\begin{array}{l}21 \cdot 5 \\
35 \cdot 5 \\
18 \cdot 0\end{array}$ & $\begin{array}{r}7 \cdot 3 \\
\text { II.0 } \\
19 \cdot 7\end{array}$ \\
\hline $23 \cdot 5$ & $\begin{array}{l}\text { Low } \\
\text { Medium } \\
\text { High }\end{array}$ & $\begin{array}{l}42 \cdot 5 \\
30 \cdot 5 \\
2 I \cdot 5\end{array}$ & $\begin{array}{r}9.0 \\
12.3 \\
17.0\end{array}$ & $\begin{array}{l}14.5 \\
32.5 \\
34.5\end{array}$ & $\begin{array}{r}6 \cdot 3 \\
10 \cdot 3 \\
22 \cdot 7\end{array}$ & $\begin{array}{l}28.0 \\
30.0 \\
15.0\end{array}$ & $\begin{array}{l}6 \cdot 0 \\
9 \cdot 3 \\
9 \cdot 7\end{array}$ \\
\hline
\end{tabular}

than that at sites $C, D$. It is possible that some coarse material found its way to the reticulum without passing through the anterior ventral sac (site $D$ ).

Mean concentrations over $24 \mathrm{~h}$ of medium-sized particles varied with sampling site in the same way as those of the coarse particles. Samples at sites $A$ and $B$ each contained about four times as much of this material as samples at sites $C$ and $D$ and about three times as much as at site $E$.

Fine particles occurred in higher mean concentrations over 24 h at sites $A$ and $B$, where the levels were about $2 \cdot 5$ times as great as at sites $C, D$ or $E$. This was not influenced by the level of intake.

The concentration of soluble and very fine material at sites $A$ and $B$ was about $20 \%$ greater than at sites $C, D$ and $E$. The level of feeding increased to a small extent the concentration of this fraction at sites $A$ and $B$ but had no significant effect at sites $C, D$ and $E$.

\section{Particle density distributions}

The distribution of particles within the range of the density columns, generally $800-1400 \mathrm{~g} / \mathrm{l}$, varied according to the sampling site, the time of sampling and the level of feeding. Samples taken from the dorsal sites ( $A$ and $B$ ) soon after feeding tended to have the highest proportion of low-density particles; those from the ventral sampling sites $(C, D$ and $E$ ) tended to have the highest proportion of high-density particles. 
To facilitate comparisons, the results from the fractionation of individual subsamples were treated in two ways: (a) by setting arbitrary limits at 1000 and $1200 \mathrm{~g} / \mathrm{l}$ and determining the concentrations of particles of density less than $1000 \mathrm{~g} / \mathrm{l}$ (low density), between rooo and $1200 \mathrm{~g} / \mathrm{l}$ (medium density), and greater than $\mathrm{I} 200 \mathrm{~g} / 1$ (high density), and ( $b$ ) by calculating mean densities, defined as:

$$
\bar{\rho}=\frac{\Sigma c \rho}{\Sigma c},
$$

where $c$ is the concentration of solid material of density $\rho$. As with size distributions, concentrations as determined by density were calculated in terms of the total sample, that is dry matter plus liquid.

\section{Mean concentrations, as determined by density}

Mean concentrations, from the three cows, of solid matter divided into the three density groups, low, medium or high, for the different sampling times, sampling sites and levels of fecding, are given in Table 4 . Taken over $24 \mathrm{~h}$ there were higher concentrations of low-density particles than of medium-density particles at sites $A$ and $B$, and the concentrations of medium-density particles were higher than those of particles of high density. At sites $C, D$ and $E$ there were higher concentrations of high-density particles than of low-density particles.

\section{Mean densities}

Mean densities, averaged over three cows, ranged from $860 \mathrm{~g} / 1$ to $\mathrm{r} 2 \mathrm{I} 0 \mathrm{~g} / \mathrm{l}$. Within this range fluctuations occurred such that there were two maxima and two minima during the $24 \mathrm{~h}$ period. Such duplex behaviour was common to all cows and all sites, with a range of periodicity of from 5 to $12 \mathrm{~h}$. Most of the short periods were close to the mean of $7.5 \mathrm{~h}$. There was no significant difference in periodicity between diets, nor was there a significant difference in periodicity between rumen sites except that the interval between minima for site $C$ was longer (a mean value of $9.5 \mathrm{~h}$ ). Mean densities at the various sites for different levels of feeding and different cows were averaged over $24 \mathrm{~h}$. There was no significant difference between sites $A$ and $B$, but mean densities at other sites increased from $A$ and $B$ to $C$ to $D$ and then decreased to $E$.

\section{Relationship between particle size and particle density}

In examining fluctuations in the concentration of solid material at any one sampling site and at any one sampling time on the basis of size and of density, it was found that in some instances a close relationship existed between the two measurements. Further evidence was sought in terms of mean concentrations over $24 \mathrm{~h}$ periods for all cows for the three fractions coarse $/ \bar{\rho}<\mathrm{r} \cdot 0$, medium $/ \mathrm{r} \cdot 0<\bar{\rho}<\mathrm{I} \cdot 2$ and fine $/ \bar{\rho}>\mathrm{I} \cdot 2$ at different sampling sites. The relevant values are plotted, concentration by size against concentration by density, in Fig. 3 to show that a $1: 1$ correspondence exists between the two measurements. An equally good correlation $(r=0.95)$ is obtained when the relationship is examined for individual cows. This suggests that, in general, large particles tended to be of low density and small particles tended to be of high density. 


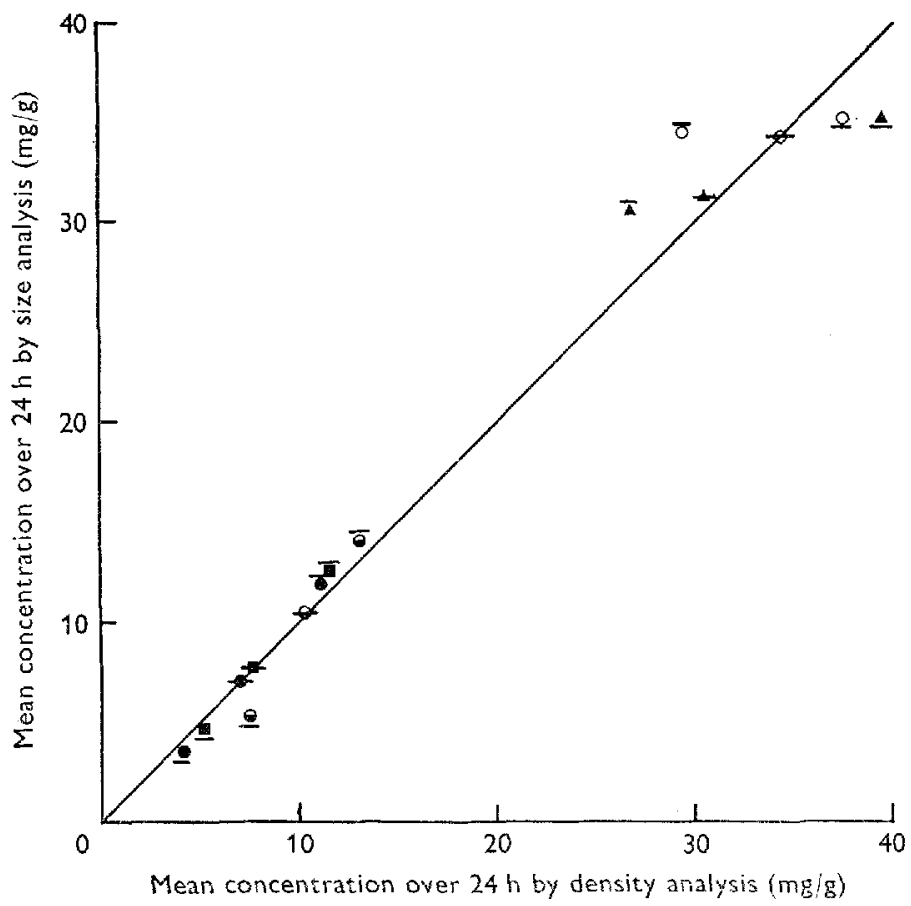

Fig. 3. Relationship between mean concentrations over $24 \mathrm{~h}$ of particles in the reticulorumen as determined by measurement of the size and density of particles. Each value is a mean for three cows on three levels $(\mathrm{H}, \mathrm{M}$ and $\mathrm{L})$ of hay. $\mathbf{A}$, site $A ; O$, site $B \mathbf{E}$, site $C$; , site $D ; \ominus$, site $E$. The position of the horizontal line relative to the symbol indicates the grade of fibre, thus: line below symbol, c.g. $\Delta$ coarse fibre, low density; line through symbol, e.g. \$ medium fibre, medium density; line over symbol, e.g. I fine fibre, high density.

Relationship between rumination and the change of concentration with time

Comparison of the times of starting and ending of rumination with features of the graphs of concentration against time indicated that there could well be a correlation between them. From density measurements, concentration-time curves were plotted to find times at which maximum and minimum concentrations occurred at each site. These were then averaged to obtain mean times for the occurrence of these maxima and minima for the reticulo-rumen as a whole. As shown in Table 5 , these fall into two groups, one around the time of commencement of rumination and one towards the end of rumination. The correlation coefficient for the start of rumination is 0.94 and for the end of rumination it is 0.57 .

It was sometimes difficult to decide the exact time at which the concentration of particles of low density was at a minimum. Moreover, for several cows neither the onset of rumination nor its completion was very clearly defined. Records of jaw movements indicated that sometimes, either at the start or at the end of rumination or both, there occurred intervals of rumination of several minutes' duration separated by longer quiescent intervals.

In view of the relationship between particle size and density concentrations indicated earlier, these characteristics of the density patterns may be translated into relationships with size. 
Table 5. Relationship between times at which concentration of material of density $>1000 \mathrm{~g} / \mathrm{l}$ attains extreme values, and onset and end of rumination

(Times for maxima and minima in concentrations are means for all five sampling sites in the rumen of three cows on three levels of hay)

\begin{tabular}{|c|c|c|c|c|c|}
\hline \multirow[b]{2}{*}{$\begin{array}{l}\text { Level of } \\
\text { feeding }\end{array}$} & \multirow[b]{2}{*}{$\begin{array}{l}\text { Cow } \\
\text { no. }\end{array}$} & \multicolumn{4}{|c|}{ Time ( $\mathrm{min}$ ) measured from mean feeding time* } \\
\hline & & $\begin{array}{l}\text { Onset of } \\
\text { rumination }\end{array}$ & $\begin{array}{l}\text { Maximum } \\
\text { concentration } \\
\text { of particles } \\
\text { of density } \\
<\text { rooo g/ } 1\end{array}$ & $\begin{array}{l}\text { End of } \\
\text { rumination }\end{array}$ & $\begin{array}{l}\text { Minimum } \\
\text { concentration } \\
\text { of particles } \\
\text { of density } \\
<1000 \mathrm{~g} / 1\end{array}$ \\
\hline \multirow[t]{3}{*}{ Low } & IO & 530 & 490 & 930 & 940 \\
\hline & 13 & 500 & 380 & 1050 & 1170 \\
\hline & 33 & 200 & 230 & 970 & 860 \\
\hline \multirow[t]{3}{*}{ Medium } & IO & 100 & I9o & 1080 & 1290 \\
\hline & I 3 & 180 & 255 & II 70 & 1120 \\
\hline & 33 & $3^{60}$ & 305 & 1210 & I 160 \\
\hline \multirow[t]{3}{*}{ High } & IO & I 35 & 150 & 1040 & 1250 \\
\hline & I 3 & I 50 & 170 & 1120 & 1170 \\
\hline & 33 & 470 & 490 & $125^{\circ}$ & 1200 \\
\hline
\end{tabular}

\section{DISCUSSION}

The significance of the results will be discussed in relation to threc factors: the extent of stratification in the reticulo-rumen, the movement of solid digesta and the kinetics of the breakdown of fibre.

\section{Stratification in the reticulo-rumen}

The general nature of vertical stratification of digesta in the reticulo-rumen of cattle was described by Schalk \& Amadon (1928), who noted an accumulation of coarse material in the dorsal sac and relatively fluid digesta in the ventral sac. They indicated how, with time after feeding, there was a tendency for mixing of the digesta to occur as a result of the regular contractions of the reticulo-rumen. Balch, Balch, Bartlett, Bartrum, Johnson, Rowland \& Turner (1955), and Balch \& Rowland (1957), referred to conditions, such as when high-concentrate-low-roughage diets were given, where stratification was not pronounced. Balch (196I) attributed the degree of stratification to the type of ration and the time after feeding, stratification being most pronounced immediately after the ingestion of a fibrous ration. However, little quantitative information has previously been available on the nature, in physical terms, of the stratification and on the rates at which changes occur in different positions.

This experiment indicated that pronounced stratification was due to the retention of newly ingested food in the dorsal regions of the reticulo-rumen. Comparison of results from samples taken at the end of the $24 \mathrm{~h}$ period $\left(T_{23} .5\right)$ with those taken immediately after feeding ( $T 2)$ showed that: $(a)$ stratification of digesta persisted throughout the $24 \mathrm{~h}$ period, the ratio of the concentration of dry matter at the dorsal sites to that at the ventral sites decreasing from 3.6 to $2 \cdot 0$ from $T_{2}$ to $T_{23}{ }^{5}$. The 
concentration of dry matter at the dorsal sites decreased and that at the ventral sites increased during this period; $(b)$ the maximum concentrations of coarse particles at the dorsal sites were at $T_{2} ;(c)$ the maximum concentrations of low-density particles at the dorsal sites and the maximum concentrations of high-density particles at the ventral sites were at $T_{2} ;(d)$ there were much higher concentrations of coarse particles at dorsal sites than at ventral sites; $(e)$ there were much higher concentrations of lowdensity particles at dorsal sites than at ventral sites.

Some of these changes in concentrations of digesta of different sizes and densities have been studied before, but fewer samplings were made. Balch et al. (1955), sampling once daily, reported dry-matter percentages of digesta from the dorsal sac which were similar to those obtained in the present experiment but their values for the ventral sac and for the reticulum were two to three times greater. Balch \& Kelly (I950) found little difference between the specific gravity of particles from the dorsal sac and the ventral sac; most of the values lay between $\mathrm{I} \cdot 022$ and $\mathrm{I} \cdot 055$. A mean specific gravity of I.OI was reported by Nichols (1959). Campling \& Freer (I962) found that most particles of specific gravity I.02-I.06 simulated stained hay particles in their rate of passage through the digestive tract. In the present experiment, pronounced changes occurred between $T_{2}$ and $T_{23}{ }^{\circ}$, but these changes were not uniform or consistent although there was a tendency towards more uniformity as time went on. In terms of particle size, the dorsal sacs showed an almost uniform decrease in the concentrations of coarse particles with time but in the ventral sacs the coarse particles reached maxima at different times during the day and then declined. Concentrations of medium-sized particles showed relatively small fluctuations but those of fine particles fluctuated to produce a bimodal pattern. The interpretation of this pattern is difficult, but it suggests that, at two periods of the day, separated by 8.5 and I $5.5 \mathrm{~h}$, the rates of production and removal of fine particles vary considerably in spite of a relatively steady decrease in the concentration of coarse particles. In measurements with sheep, Pearce (r967) showed similar changes in the concentrations of coarse and medium-sized particles but only a unimodal pattern for fine particles.

Completely consistent behaviour in these terms would not be expected because of the impact of rumination at different times during the day. As well as causing a reorganization of particle distribution, the extra salivary flow during rumination would be expected to affect concentrations of particle grades. Correlations between the start and end of a day's rumination indicated the possibility of association with certain maximum and minimum concentrations.

\section{Movement of solid digesta in the rumen}

Density and size results together provide an indication of how particulate matter moves in the rumen. The mean densities for all three cows for different sites and sampling times are given in Table 6. Minimum density, indicative of the occurrence of maximum concentration of lighter, coarser material occurred early after feeding at sites $A$ and $B$, as would be expected, and progressively later at sites $C, D$ and $E$. The density at the dorsal site $A$ at any time was lower than at the corresponding ventral site $D$ and, similarly, density at site $B$ was lower than at site $C$. 
Table 6. Mean densities $(\mathrm{g} / \mathrm{l})$ of fibrous digesta taken at each of six sampling times from sampling sites $A$ to $E$ in the reticulo-rumen of three cows on three levels of hay

(The minimum density for each site is in bold-faced type)

\begin{tabular}{|c|c|c|c|c|c|c|}
\hline \multirow[b]{2}{*}{$\begin{array}{l}\text { Level of } \\
\text { feeding }\end{array}$} & \multirow[b]{2}{*}{$\begin{array}{l}\text { Sampling } \\
\text { time* }\end{array}$} & \multicolumn{5}{|c|}{ Density at site } \\
\hline & & $A$ & $B$ & $C$ & $D$ & $E$ \\
\hline \multirow[t]{6}{*}{ High } & 2 & 1070 & 1080 & 1090 & II 70 & I 180 \\
\hline & $4 \cdot 5$ & 1050 & 1030 & I I 80 & I I 40 & IIIO \\
\hline & $7 \cdot 5$ & 1050 & 1030 & I 130 & xo6o & I I ro \\
\hline & II' 5 & 1070 & I 120 & 1060 & 1130 & 1130 \\
\hline & $19 \cdot 5$ & 1100 & I 120 & I I 50 & 1180 & 1080 \\
\hline & $23 \cdot 5$ & rorot & 1060 & II 50 & I I 70 & 1030 \\
\hline \multirow[t]{6}{*}{ Medium } & 2 & I I 00 & 1070 & I I 50 & 1210 & I 180 \\
\hline & $4 \cdot 5$ & 1060 & 1020 & I I 90 & 1160 & 1160 \\
\hline & $7 \cdot 5$ & 1070 & Iogo & IIIO & I I 90 & I 120 \\
\hline & II 5 & I 100 & 1060 & I I 50 & 1210 & 1120 \\
\hline & 19.5 & 1020 & I I 20 & 1200 & II5o & IIIO \\
\hline & 23.5 & 1160 & I I IO & I I 80 & 1160 & 1150 \\
\hline \multirow[t]{6}{*}{ Low } & 2 & Io3o & I I 00 & I I 40 & I 120 & 1170 \\
\hline & $4 \cdot 5$ & 1050 & 910 & $x 080$ & 1130 & I I 20 \\
\hline & $7 \cdot 5$ & 1000 & 990 & IOgO & 1070 & I I IO \\
\hline & I I 5 & 1020 & 1080 & I I 20 & $\operatorname{II} 30$ & 1060 \\
\hline & $19 \cdot 5$ & I 100 & 1060 & I I 20 & 1180 & 1170 \\
\hline & 23.5 & 1090 & 990 & I I 00 & I 130 & Ir $5^{\circ}$ \\
\hline
\end{tabular}

Two features of this table are relevant to the argument on the movement of digesta, namely that minimum density occurred earliest at $B$ and not at $A$, and that the density was a minimum progressively later for sites $B, C, D$ and $E$.

These observations may be explained by cyclic movement of digesta from the dorsal sac, around the posterior ventral region to the ventral region and thence to the reticulum. That the minimum density occurred later at site $A$ than at site $B$ may be explained on the same basis if the cycle of movement of coarser material did not end at the reticulum but continued to the anterior dorsal site $A$. An influx of material into site $A$ from site $E$, of a mean density higher than that of new food entering the dorsal sac, by virtue of the fact that it had been digested to some extent by passage around the rumen, would have had the effect of raising the mean density at site $A$ early in the cycle. The density at site $A$ would have decreased progressively during rumination as this partly digested material from the previous cycle was ruminated upon and removed.

Results for concentration of coarse particles support the density results in that the maximum concentration of coarser material occurred soon after feeding at the dorsal sites, but not until towards the end of the $24 \mathrm{~h}$ period at the ventral sites.

The question to be answered was what happened to coarser material at ventral sites on feeding, the two possibilities being expulsion or recirculation. The difference between the concentration of coarse material at ventral sites at $T_{23.5}$ and at the time of the first sampling was appreciable, and almost invariably there was a greater concentration at $T_{23} \cdot 5$ than at $T_{2}$. 
Table 7 . Changes in concentration ( $\mathrm{g} / \mathrm{kg}$ of sample $\times 100$ ) of coarse particles (sieves $\mathrm{I}$ and 2) measured at dorsal $(A$ and $B)$ and ventral $(C, D$ and $E$ ) sites in the reticulo-rumen during feeding

(Values are means for three cows on three levels of hay; each value is the difference in concentration between the first sampling after feeding $(T 2)$ and the last sampling before feeding $(T 23 \cdot 5))$

\begin{tabular}{|c|c|c|c|c|c|c|c|}
\hline \multirow[b]{2}{*}{$\begin{array}{l}\text { Level of } \\
\text { feeding }\end{array}$} & \multicolumn{3}{|c|}{ Increase at sites $A$ and $B$} & \multicolumn{3}{|c|}{ Decrease at sites $C, D$ and $E$} & $\begin{array}{c}\text { Estimated } \\
\text { increase } \\
\text { (due to feed) } \\
\text { at sites } A \text { and } B\end{array}$ \\
\hline & Sieve I & Sieve 2 & Sieves I and 2 & Sieve I & Sieve 2 & Sieves I and 2 & Sieves 1 and 2 \\
\hline Low & 5180 & 400 & 5580 & 440 & 470 & 910 & 4670 \\
\hline Medium & 6860 & 1230 & 8090 & 150 & 440 & 590 & 7500 \\
\hline High & 8740 & 800 & 9540 & 120 & 510 & 630 & 8910 \\
\hline
\end{tabular}

Intake of new, coarse fibre into the rumen should have increased the concentration of this fraction at dorsal sites in the ratio $3: 5: 7$ and the results indicate that the concentration of coarse material increased at dorsal sites only. The results indicated that this increase in concentration of coarse material at the dorsal sites was in the ratio 5580:8090:9540 $=\mathrm{I}: 1 \cdot 45: \mathrm{I} \cdot 7 \mathrm{I}$ (Table 7), whereas the ratio to be expected was $3: 5: 7$ or $1: 1 \cdot 67: 2 \cdot 33$. In actual fact, cows given $7 \mathrm{~kg} / \mathrm{d}$ rejected on average $1 \cdot 16 \mathrm{~kg} / \mathrm{d}$ on their sampling days; so the ratio to be expected was $1: 1 \cdot 67: 1 \cdot 94$. If changes in the size of the rumen on feeding could be ignored and the assumption were made that the coarser material from the ventral sites could be recycled to the dorsal sites during feeding, it would be necessary to subtract this element of concentration from the values given above in order that the increase in concentration at the dorsal sites should match the ration ratio. From Table 7 the new ratio that results is $4670: 7500: 8910=$ $I: I \cdot 6 I: I \cdot 9 \mathrm{I}$, which is close to the expected value. One possibility that may warrant further investigation, therefore, is that a significant part of the coarser element of digesta in the reticulum is returned to the dorsal sacs on feeding, to be recirculated with the new feed.

It is of interest to consider what happened, on feeding, to particulate matter at the other end of the size range. Table 8 gives values of the ratio:

$$
\frac{\text { concentration after feeding }\left(T_{2}\right)}{\text { concentration before feeding }\left(T_{23} \cdot 5\right)}
$$

for the fine fraction and for the fraction passed by the finest screen, which was mostly composed of soluble solids. There was no great change in concentration of very finely divided particles and of soluble solids in the reticulo-rumen during this period; neither was there any appreciable change in concentration of fine particles at dorsal sites, whereas the concentration of this size of particle at all three ventral sites was approximately halved.

This halving of the concentration at ventral sites may have been due either to dilution on drinking or to movement of finely divided material out of the reticulorumen, there being no corresponding increase in concentration of this size of particle 
Table 8. Ratio of the concentration at the first sampling after feeding (T2) to the concentration at the last sampling before feeding $\left(T_{23} \cdot 5\right)$ for fine particles at each of the five sampling sites $(A-E)$ in the reticulo-rumen of cows on three levels of hay

(Mean values for three cows)

\begin{tabular}{|c|c|c|c|c|c|c|}
\hline \multirow[b]{2}{*}{ Particle size } & \multirow[b]{2}{*}{ Level of feeding } & \multicolumn{5}{|c|}{ Ratio at site: } \\
\hline & & $A$ & $B$ & $C$ & $D$ & $E$ \\
\hline Fine & $\begin{array}{l}\text { Low } \\
\text { Medium } \\
\text { High }\end{array}$ & $\begin{array}{l}0.63 \\
0.94 \\
I .02\end{array}$ & $\begin{array}{l}1.05 \\
0.85 \\
0.75\end{array}$ & $\begin{array}{l}0.51 \\
0.34 \\
0.63\end{array}$ & $\begin{array}{l}0.33 \\
0.50 \\
0.47\end{array}$ & $\begin{array}{l}0.44 \\
0.53 \\
0.40\end{array}$ \\
\hline Soluble and very fine & $\begin{array}{l}\text { Low } \\
\text { Medium } \\
\text { High }\end{array}$ & $\begin{array}{l}I \cdot 02 \\
0.48 \\
I \cdot I 5\end{array}$ & $\begin{array}{l}0.98 \\
0.85 \\
0.67\end{array}$ & $\begin{array}{l}I \cdot I 6 \\
I \cdot O r \\
I \cdot 03\end{array}$ & $\begin{array}{l}0.91 \\
0.78 \\
1.04\end{array}$ & $\begin{array}{l}I \cdot 23 \\
I \cdot 12 \\
I \cdot 33\end{array}$ \\
\hline
\end{tabular}

at dorsal sites. The results for concentration of the fine solids and solids in solution do not indicate that there was dilution due to eating and drinking, so that the conclusion is that some particles less than $2 \mathrm{~mm}$ in length were expelled from the reticulorumen during feeding.

In summary, therefore, the picture that emerges is of cyclic movement of coarse digesta from ventral to dorsal sites on feeding while some of the finer digesta are removed from the reticulo-rumen. It is a little surprising that there was no change in the concentration of extremely fine particulate matter and of soluble solids during eating and drinking.

Some further indication of the possible movement of material within the reticulorumen is provided by the density results. At any time of sampling, the mean density at dorsal sites $A$ and $B$ was lower than at adjacent ventral sites $D$ and $C$ respectively. Mean density varied with time in a similar manner for a dorsal site and for its ventral neighbour (e.g. $A, D$ and $B, C$ ). The behaviour for site $E$ was complex, conforming to the pattern for sites $B$ and $C$ for about $5 \mathrm{~h}$ after feeding and thereafter changing over to conform with the general pattern for sites $A$ and $D$.

The implication of the similarity in density variation between vertically adjacent sites is that interchange of digesta could occur direct between such sites as well as by cyclic movement of digesta around the rumen, as discussed later. Such direct interchange may result from recurrent and frequent movement of liquor in a vertical plane during contractions of the rumen.

\section{Kinetics of breakdown of fibre}

Comminution of fibrous material in the reticulo-rumen may be regarded as involving the transfer from a large-particle, rumination pool to a small-particle pool that discharges into the abomasum (Hungate, I966).

The relevant equations for emptying of the two pools are:

$$
d L / d t=-K_{L} L \text { and } d S / d t=K_{L} L-K_{S} S .
$$

In this analysis $L$ and $S$ are mean concentrations, over the entire reticulo-rumen, of particles classed as being in the rumination (large-particle) pool and in the small- 


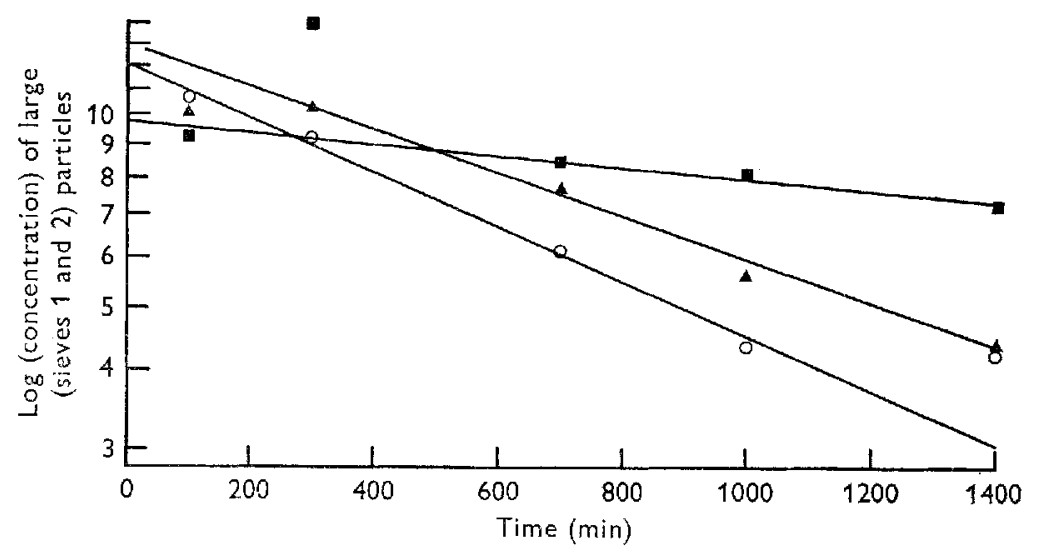

Fig. 4. Concentration of coarse particles of hay (retained by sieves $\mathbf{I}$ and 2 ), with time, for three cows on the low level of hay. Concentrations $(\mathrm{mg} / \mathrm{g})$ are mean values for five sites $(A-E)$, in the reticulo-rumen. $\mathbf{n}$, cow $33 ; \mathbf{A}$, cow ro; $O$, cow 13 .

particle pool respectively. $K_{L}$ and $K_{S}$ are rate constants for transfer of particulate matter out of the two pools.

The solutions of the differential equations ( $\mathrm{I}$ ) are:

$$
\left.\begin{array}{c}
L=L_{0} e^{-K_{L} t} \quad \text { or } \quad \ln L / L_{0}=-K_{L} t, \\
S=I_{0} K_{L} /\left(K_{S}-K_{L}\right)\left(e^{-K_{L} t}-e^{-K_{S} t}\right) .
\end{array}\right\}
$$

Particles held by screen I, the coarse particles, or alternatively by screens I and 2 , were classed as being in the rumination pool and particles passing screen 3 were considered to be in the small-particle pool. The concentrations of particles held by screen 3 were relatively constant with time, and particles of this size were therefore considered to be a transition size between large and small-particle pools.

Graphs of concentration against time for particles in the large-particle pool are given in Fig. 4 and for particles in the small-particle pool in Fig. 5.

The constants $K_{L}$ are given by the slope of the graphs in Fig. 4 and the constants $K_{S}$ are obtained from the graphs in Fig. 5 at time $\tau$ such that $(d S / d t)=0$ and $K_{S}=$ $K_{L}\left(L_{\tau} / S_{\tau}\right)$, where $L_{\tau}$ and $S_{\tau}$ are the concentrations of fibre in the two pools at time $\tau$. Values of $K_{S}$ and $K_{L}$ for the three cows and three rations are given in Table $9(a)$, the assumption being that only the largest fibrous particles (average length $9.3 \mathrm{~mm}$ ) constituted the rumination pool. The extent to which these constants are modified by assuming that the largest-particle pool consisted of particles of $6.9 \mathrm{~mm}$ average length may be judged from the values given for cow 13 in Table $9(b)$.

One assumption made in developing this argument that is particularly open to challenge is that each sampling station was representative of one-fifth of the total volume of the rumen, or alternatively that the mean concentration of particulate matter of any size range in the rumen was given by the mean of the concentrations at five sampling sites. The magnitude of the errors introduced by this assumption should 


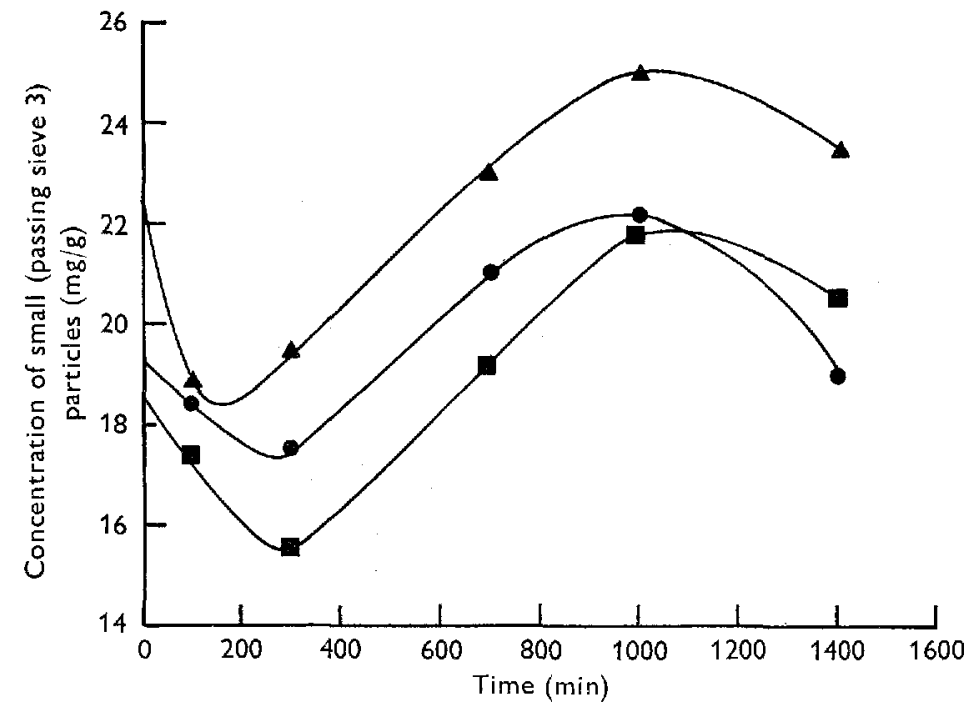

Fig. 5. Concentration of small particles of hay (passing sieve 3) with time, for three cows on the low level of hay. Concentrations $(\mathrm{mg} / \mathrm{g})$ are mean values for five sites $(A-E)$, in the reticulo-rumen, $\mathbf{E}$, cow $33 ; \mathbf{A}$, cow $10 ; \boldsymbol{\theta}, \operatorname{cow} \mathbf{1}_{3}$.

Table 9. Rate constants $K_{L}$ and $K_{S}$ ( $\times 10^{4}$ per min) for the large- and small-particle pools respectively, as a function of the average concentration of large and small particles in the reticulo-rumen of cows at $T=0$ as unity

Level of feeding $\overbrace{K_{L}{ }_{K_{S}}}^{\text {Cow 10 }} \overbrace{K_{L}}^{\text {Cow 13 }} \overbrace{K_{S}}^{\text {Cow 33 }}$

(a) Rumination pool consisting of particles of average length $9.3 \mathrm{~mm}$

$\begin{array}{lrrrrrr}\text { Low } & 8 \cdot 2 & 3 \cdot 7 & 9 \cdot 8 & 4 \cdot 1 & 1 \cdot 9 & 1 \cdot 4 \\ \text { Medium } & 10 \cdot 2 & 3 \cdot 6 & 10 \cdot 2 & 3 \cdot 6 & 4 \cdot 4 & 2 \cdot 4 \\ \text { High } & 8 \cdot 4 & 3 \cdot 7 & 7 \cdot 8 & 3 \cdot 0 & 5 \cdot 7 & 4 \cdot 3\end{array}$

(b) Rumination pool consisting of particles of average length $6.9 \mathrm{~mm}$

$\begin{array}{lllllll}\text { Low } & - & - & 6 \cdot 7 & 4.9 & - & - \\ \text { Medium } & - & - & 6 \cdot 3 & 4 \cdot 0 & - & \text { - } \\ \text { High } & - & - & 6.9 & 4.3 & - & -\end{array}$

not, however, be overestimated for it can be shown that, because the coarse pool consisted mainly of material at sites $A$ and $B$, the constants are barely affected by a doubling of the volumes at all three ventral sampling sites. Similarly, a doubling of the volumes at both of the dorsal sampling sites relative to the ventral has very little effect. A doubling of the volume at one of the dorsal sites changes the constant for the rumination pool by about $10 \%$, which is not a large factor, bearing in mind the many other sources of error in this type of experiment.

Another consideration that enters into discussion of rumen kinetics is change in size of the rumen with time, and the analysis indicates that this has no effect on the value deduced for $K_{L}$ provided all sampling sites suffer a volume change proportional to the change in rumen volume. 
Similarly, effective sampling volumes do have a bearing on the values of $K_{S}$, but if the volume of any site is doubled $K_{S}$ is changed only by about 10\%.

The turnover constants were similar for two of the three cows, Io and I3, used in the experiment but quite different for the third cow, 33. Moreover, there was no effect of ration on the constants for cows 10 and 13 but 33 showed an increase in both constants with ration, $K_{L}$ increasing linearly with concentration.

A turnover time defined by $\tau=\mathrm{I} / K$ is $\mathrm{I}$ I $00 \mathrm{~min}$ ( $18 \mathrm{~h}$ ) for cows $\mathrm{IO}$ and $\mathrm{I} 3$ for the coarsest fraction and $277^{\circ} \mathrm{min}(46 \mathrm{~h})$ for the finest particles which includes all soluble solids and bacteria.

The extent to which rate-constants and turnover times are changed by including in the coarsest fraction material retained by sieves $\mathrm{I}$ and 2 rather than by sieve $\mathrm{I}$ only may be judged by comparing Table $9(a)$ and $(b)$. These results indicate that, for cow 13, $K_{L}$ is reduced from $9.7 \times 1 \mathrm{IO}^{-4}$ per min to $6.6 \times \mathrm{ro}^{-4}$ per min and $K_{S}$ is increased from $3.6 \times \mathrm{IO}^{-4}$ to $4.4 \times \mathrm{IO}^{-4} \mathrm{per}$ min. The corresponding turnover times are $25 \mathrm{~h}$ for larger particles and $38 \mathrm{~h}$ for small particles.

These results may be compared with those of Blaxter, Graham \& Wainman (1956) for sheep fed on long, dried grass, for which the turnover time, $t=\mathrm{I} / K$, for transfer from the rumen to the abomasum varied from $3^{2} \mathrm{~h}$ for a daily ration of $600 \mathrm{~g}$ to $15.6 \mathrm{~h}$ for a ration of $x 500 \mathrm{~g}$.

This work was carried out while one of us (G. R. P.) was on sabbatical leave from the University of Melbourne, Victoria, Australia. He is indebted to Professor B. G. F. Weitz, Director of the National Institute for Research in Dairying for permitting him to spend time at the Institute. The authors wish to thank Dr C. C. Balch, Head of the Department of Feeding and Metabolism, for much encouragement and advice.

\section{REFEREN CES}

Balch, C. C. (1949). Some factors influencing the intake and digestion of foods by dairy cows. PhD Thesis, University of Reading.

Balch, C. C. (1950). Br. F. Nutr. 4, 361.

Balch, C. C. (1958). Outl. Agric. 2, 33.

Balch, C. C. (1961). In Digestive Physiology and Nutrition of the Ruminant, ch. 3, p. 23 [D. Lewis, editor]. London: Butterworths.

Balch, C. C., Balch, D. A., Bartlett, S., Bartrum, M. P., Johnson, V. W., Rowland, S. J. \& Turner, J. (1955). \%. Dairy Res. 22, 270 .

Balch, C. C. \& Kelly, A. (1950). Br. F. Nutr. 4, 395.

Balch, D. A. \& Rowland, S. J. (1957). Br. F. Nutr. Ir, 288.

Blaxter, K. L., Graham, N. McC. \& Wainman, F. W. (1956). Br. F. Nutr. ro, 69.

Campling, R. C. \& Freer, M. (I962). Br. F. Nutr. 16, 507.

Hungate, R. E. (1966). The Rumen and Its Microbes, ch. 5. New York and London: Academic Press.

Magee, H. E. (1932). F. exp. Biol. 9, 409.

Nichols, R. E. (1959). Res. Rep. Wisc. agric. Exp. Stn no. 3.

Pearce, G. R. (1967). Aust. F. agric. Res. 18, i19.

Schalk, A. F. \& Amadon, R. S. (1928). Bull. N. Dak. agric. Exp. Stn no. 2 I6.

Troelsen, J. E. \& Campbell, J. B. (xg68). Anim. Prod. ro, 289.

Welch, J. G. (1965). F. Anim. Sci. 24, 9 II. 